\title{
STATISTICAL ESTIMATION OF WAVE CLIMATES IN A MONSOON REGION
}

\author{
Akira Kimura $^{1}$ and Takao Ota ${ }^{2}$
}

\begin{abstract}
This paper deals with a statistics of wave climate. NOWPHAS data from 7 observatories along the Sea of Japan coast are investigated. Fourier spectrum of one year time series of significant wave height $H_{1 / 3}$ shows inherent characteristic to the monsoon region. It can be divided into three frequency regions; (A) $f<0.006 d^{-1}$, (B) $0.006 d^{-1}<f<0.2 d^{-1}$ and (C) $0.2 d^{-1}<f<2 d^{-1}$ where $d^{-1}=1 /$ day. Simple but appropriate spectrum modeling for the region is proposed in this study. It is possible to make Monte-Carlo simulations of wave climates applying the model very easily. All statistical properties can be calculated from the simulated data. No formulation for the frequency distribution of wave properties such as annual maximum wave height is necessary. Some useful applications of the present study are shown in the last.
\end{abstract}

Keywords: wave climate, spectrum of a time series of $H_{1 / 3}$, simulation of wave statistics, Monte-Carlo method

\section{INTRODUCTION}

Design manual for public structures revised in Japan in 2007. The new manual adopts a concept of performance based design. Slight failures of a structure are allowed as far as the structure keeps the demanded performance. In the former manual, a specification based design was used so that damage must not occur during the lifetime. Design wave conditions were determined applying an extreme value statistics (Goda, 2000). After the revision, it becomes necessary to estimate all waves which may damage the structure during its lifetime. For better design and management of structures after the revision, statistics of wave climate become necessary. However the number of relating researches is very limited. Hirose et al., (1982) showed that a frequency distribution of a daily averaged $H_{1 / 3}$ is very close to the Weibull distribution. A difficult point in wave climate study is that some data in the population have correlations. However statistic theory demands the data independency. On the other hand, it is necessary to show the wave climates in a simple form for its better application to the life cycle management (LCM) of the structure. The present study aims to overcome the restriction of the theory and to clarify statistical characteristics of the wave climates. A spectrum concept is introduced. Wave data from 7 observatories (NOWPHAS) along the Sea of Japan coast from 1991 to 2008 (18 years) were investigated and showed one year time series of $H_{1 / 3}$ have a inherent spectral characteristic to the monsoon region regardless of the observatories and years. The spectrum can be divided into three frequency regions, (A) $f<0.006 d^{-1}$, (B) $0.006 d^{-1}<f<$ $0.2 d^{-1}$ and (C) $0.2 d^{-1}<f<2 d^{-1}$ where $d^{-1}=1 /$ day. The spectrum in the region (A) decides the seasonal change of $H_{1 / 3}$ with a small number of Fourier components. Very simple modeling for the regions (B) and (c) are possible. Statistical properties of wave climates are simulated by Monte-Carlo method using the models. The present study is applicable to study not only wave climates but also extreme wave statistics. Some applications which may be useful in the LCM are shown in the last.

\section{STATISTICAL PROPERTIES OF THE OBSERVED DATA}

The present method bases on the observed data from 7 observatories. Figure 1 shows the locations of the observatories. Figures 2(a) and 2(b) show examples of one year $H_{1 / 3}$ data (observed every 2 hours). These figures show the data from the coast in the north and center of the Sea of Japan (Fig.1). The numbers in the horizontal axis are the days counted from Jan. $1^{\text {st }}$. Here after the same horizontal axis is used. Data in the both ends of the figures (winter) are large, and small in the center part (summer). The term "monsoon" in the title of the present study means that data (wave climate) show seasonal characteristics like Fig.2. Figures 3(a) and 3(b) show spectra (absolute value) of one year time series of $H_{1 / 3}$. The spectrum $F^{\prime}\left(f_{n}\right)$ is given by

$$
F^{\prime}\left(f_{n}\right)=\sum_{i=1}^{4380} H_{1 / 3}\left(t_{i}\right) \exp \left(-j 2 \pi f_{n} t_{i}\right), \quad(n=0,1,2, \cdots, 2190)
$$

in which $j=\sqrt{-1}, f_{n}=n / 365 \cdot d^{-1}$ is a discrete frequency with an interval of $1 / 365 \cdot d^{-1}$ where $d^{-1}=$ $1 /$ day, $t_{i}(i=1,2, \cdots, 4380)$ is a time sequence with 2 hours interval, data number of one year total is 4380 $(=12 \times 365) .\left|F^{\prime}\left(f_{n}\right)\right|$ in Figs. 3(a) and 3(b) show the shape that looks like very well. Figure 4 shows a pattern diagram of the shape. The spectrum can be divided into 3 frequency regions. Their frequency region and characteristic are listed in Table 1. The upper bound of the region in (C) $f<2 d^{-1}$ is set to avoid aliasing effect.

In this study, totally 128 years $H_{1 / 3}$ ( 7 observatories $\times 18$ years) are investigated. Due to space limitation, only limited number of results is shown here after. However there are no significant differences between the shown and other cases.

\footnotetext{
${ }_{1}^{1}$ NEWJEC, Koyama Kita 6-448-69, Tottori, 680-0941, Japan

2 Tottori Univ., Faculty of Eng., Koyama Minami 4-101, Tottori, 680-8552, Japan
} 


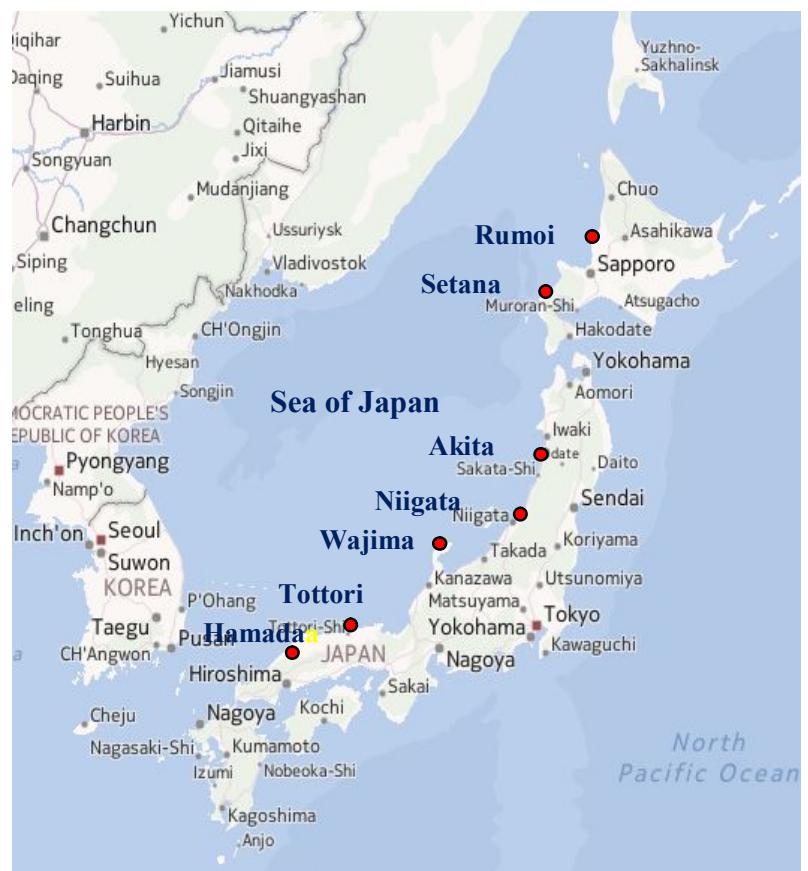

Figure 1. Locations of observatories.

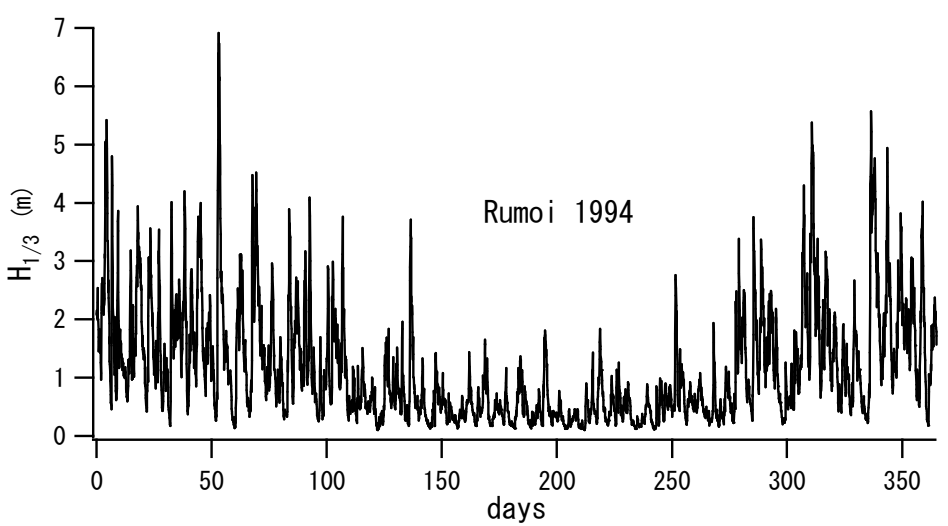

(a) Rumoi (1994)

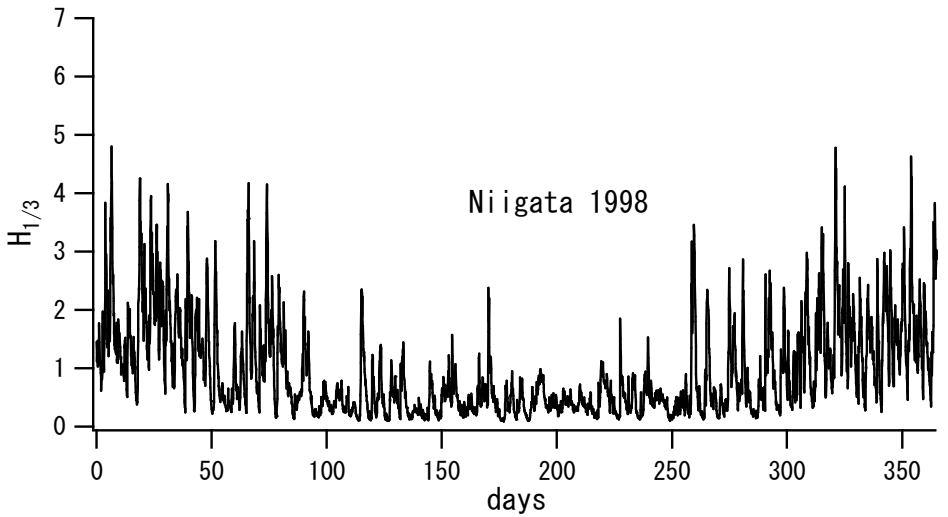

(b) Niigata (1998)

Figure 2. Observed one year time series of $H_{1 / 3}$, (a) Rumoi (1994) and (b) Niigata (1998)

\section{COMPONENTS FROM 3 FREQUENCY REGIONS}

\section{Seasonal characteristics}

$H_{1 / 3}(t)$ can be written as sum of components from 3 regions. 


$$
H_{1 / 3}(t)=H_{A}(t)+H_{B}{ }^{\prime}(t)+H_{C}{ }^{\prime}(t)
$$

in which $H_{A}, H_{B}{ }^{\prime}$ and $H_{C}{ }^{\prime}$ are wave forms from each region $\mathrm{A}, \mathrm{B}$ and $\mathrm{C}$ respectively. They are given by the inverse Fourier transformations.

$$
\left.\begin{array}{rl}
H_{A}\left(t_{i}\right) & =\sum_{n=0}^{2} F^{\prime}\left(f_{n}\right) \exp \left(j 2 \pi f_{n} t_{i}\right) \\
H_{B}{ }^{\prime}\left(t_{i}\right) & =\sum_{n=3}^{73} F^{\prime}\left(f_{n}\right) \exp \left(j 2 \pi f_{n} t_{i}\right) \\
H_{C}{ }^{\prime}\left(t_{i}\right) & =\sum_{n=74}^{731} F^{\prime}\left(f_{n}\right) \exp \left(j 2 \pi f_{n} t_{i}\right)
\end{array}\right\} \quad(i=1,2, \cdots, 4380)
$$

in which $t_{i}$ is the time (NOWPHAS data every 2 hours), $f_{2} \approx 0.006 d^{-1}, f_{73}=0.2 d^{-1}$ and $f_{731} \approx 2 d^{-1}$ (Table 1). Figures 5(a) 5(d) show the examples: 5(a) $H_{1 / 3}\left(t_{i}\right), 5(\mathrm{~b}) H_{A}\left(t_{i}\right), 5(\mathrm{c}) H_{B}{ }^{\prime}\left(t_{i}\right)$ and 5(d) $H_{C}{ }^{\prime}\left(t_{i}\right)$ (Tottori, 2000).

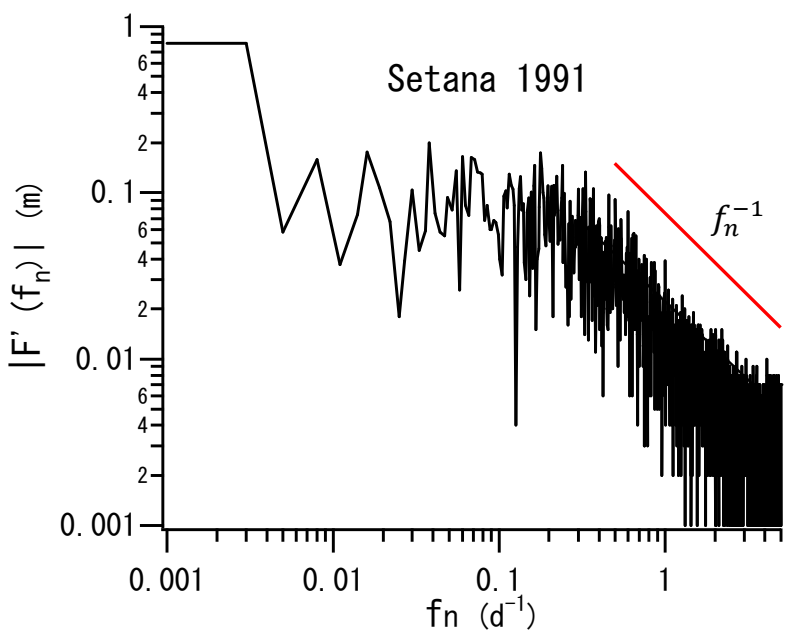

(a) Setana (1991)

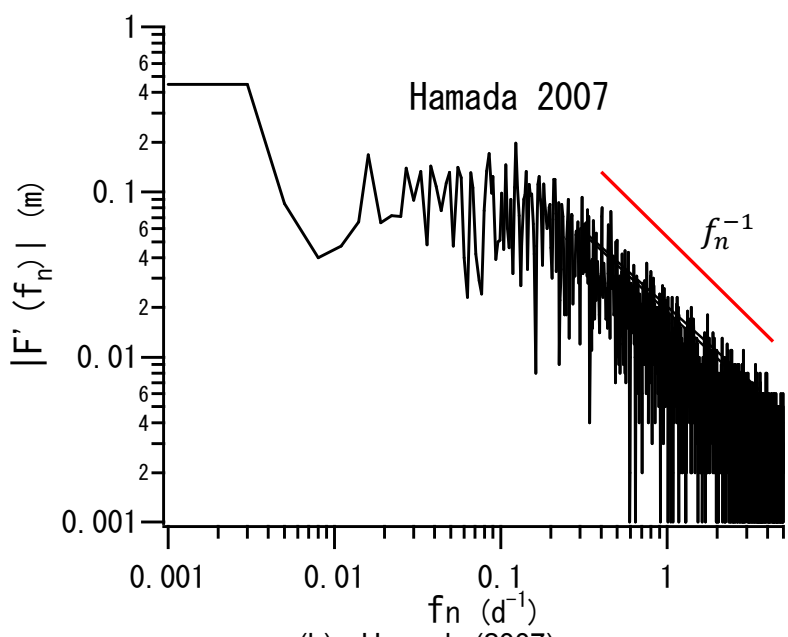

(b) Hamada (2007)

Figure 3. Spectrum $\left|F^{\prime}(f)\right|$ of the observed one year time series of $H_{1 / 3}$ 


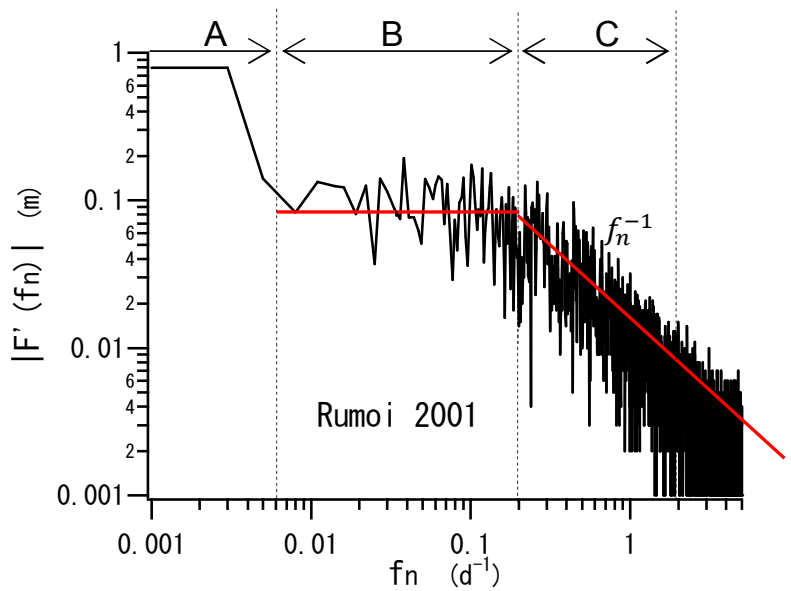

Figure 4. Pattern diagram of the spectrum

\begin{tabular}{|c|c|l|}
\hline \multicolumn{3}{|c|}{ Table 1 Frequency regions and characteristics } \\
\hline Region & $f_{n}\left(d^{-1}\right)$ & \multicolumn{1}{c|}{$F\left(f_{n}\right)$} \\
\hline A & $\sim 0.006$ & quick decrease with $f_{n}$ \\
\hline B & $0.006 \sim 0.2$ & almost constant \\
\hline C & $0.2 \sim 2$ & decrease in proportion to $f_{n}^{-1}$ \\
\hline
\end{tabular}
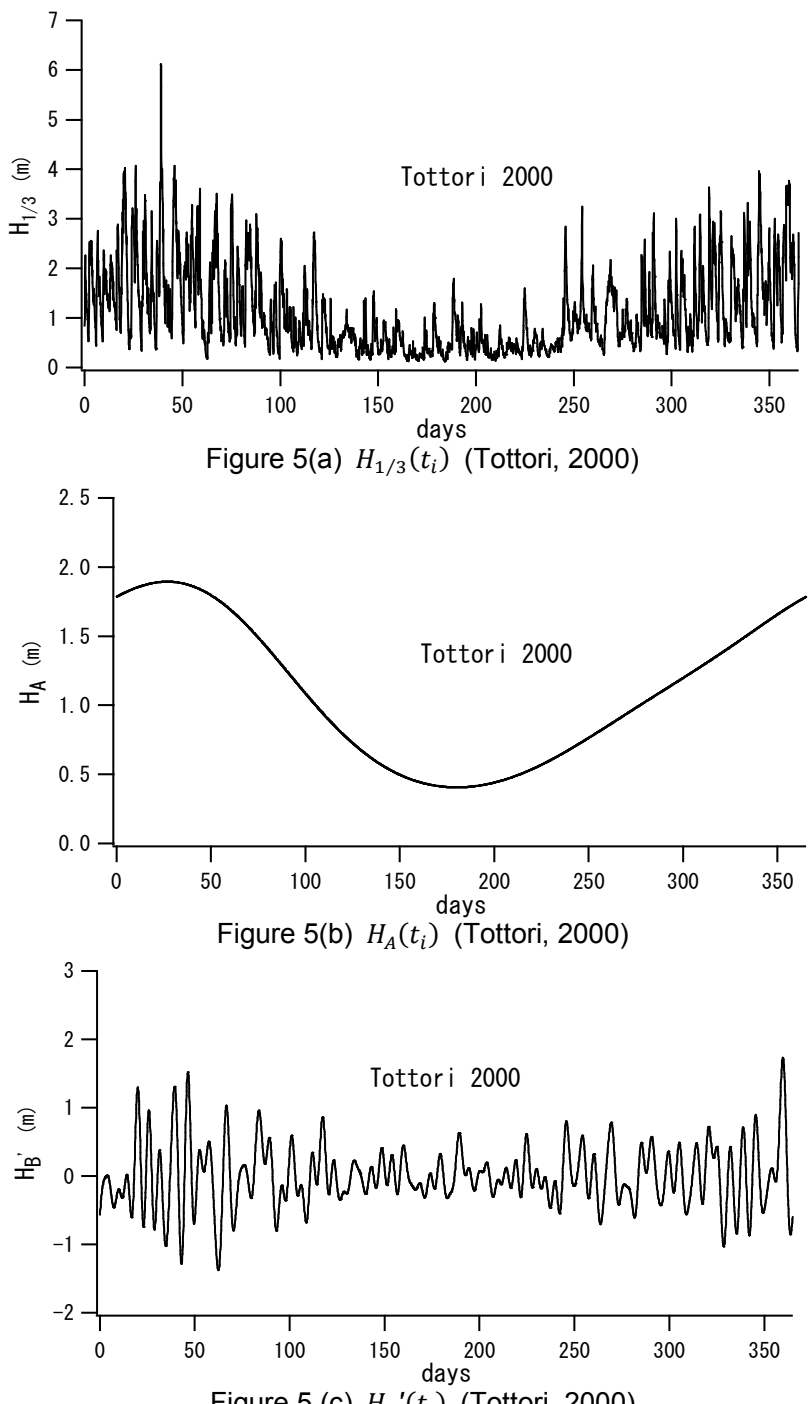

Figure 5 (c) $H_{B}{ }^{\prime}\left(t_{i}\right)$ (Tottori, 2000) 


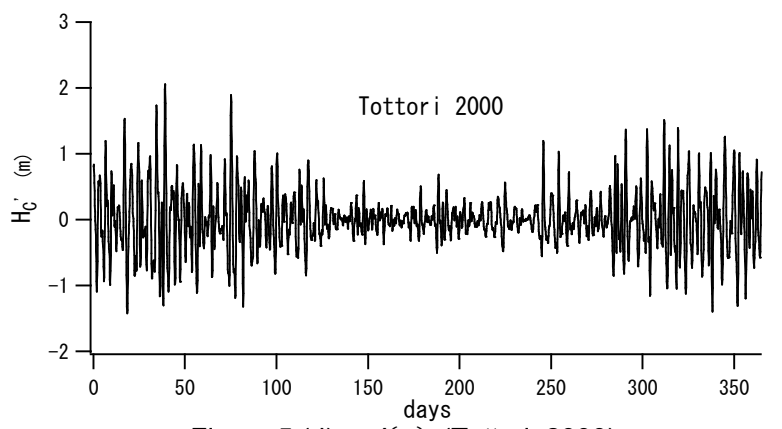

Figure $5(\mathrm{~d}) H_{C}^{\prime}\left(t_{i}\right)$ (Tottori, 2000)

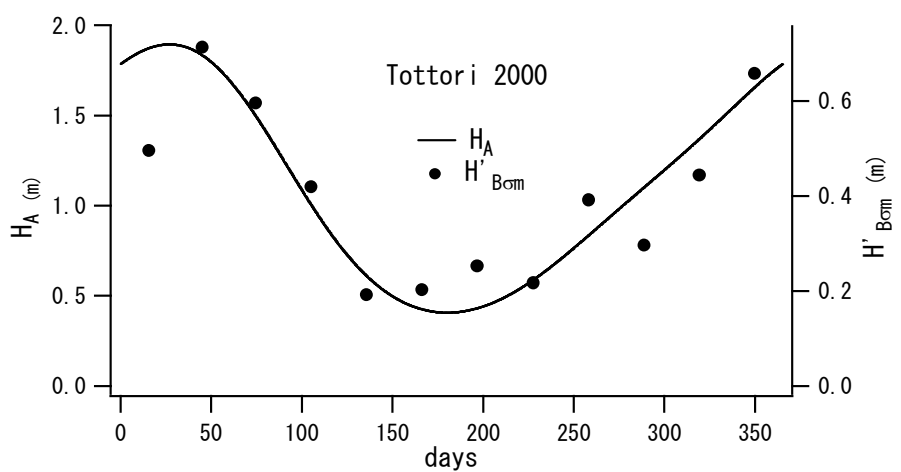

(a) $H_{A}\left(t_{i}\right)$ and $H_{B \sigma m}^{\prime}\left(t_{l}\right)$

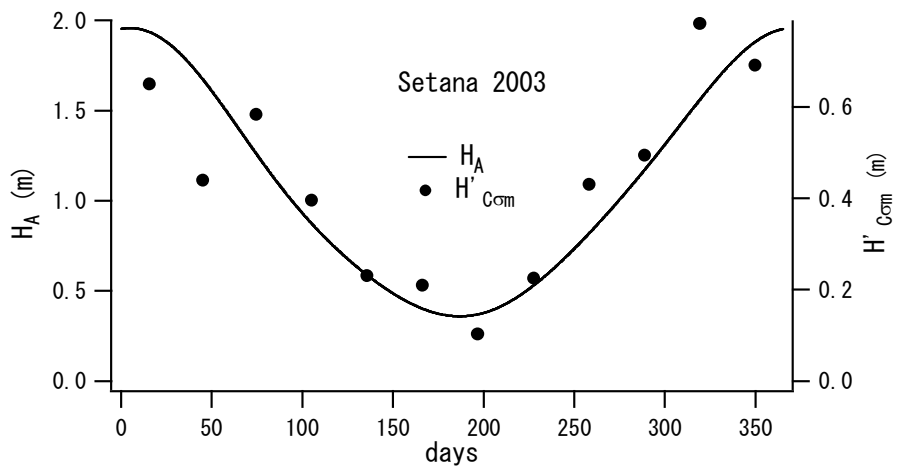

(b) $H_{A}\left(t_{i}\right)$ and $H_{C \sigma m}^{\prime}\left(t_{l}\right)$

Figure 6. Comparison between $H_{A}\left(t_{i}\right)$ (solid line ; left axis) and monthly standard deviation (black circle ; right axis) of (a) $H_{B}{ }^{\prime}(t)$ (Tottori, 2000) and (b) $H_{C}{ }^{\prime}(t)$ (Setana,2003)

Figures 6(a) and 6(b) show comparisons between $H_{A}\left(t_{i}\right)$ (left axis) and the standard deviation of (a) $H_{B}{ }^{\prime}\left(t_{i}\right)$ and (b) $H_{C}{ }^{\prime}\left(t_{i}\right)$ (right axis), respectively. $H_{B \sigma m}^{\prime}\left(t_{l}\right)$ and $H_{C \sigma m}^{\prime}\left(t_{l}\right)$ are the monthly standard deviation of $H_{B}{ }^{\prime}\left(t_{i}\right)$ and $H_{C}{ }^{\prime}\left(t_{i}\right) . t_{l}(l=1, \cdots, 12)$ is a day at center every month. In the both figures, good agreements are observed. This means that seasonal characteristics of $H_{B}{ }^{\prime}(t)$ and $H_{C}{ }^{\prime}(t)$ are almost proportional to $H_{A}\left(t_{i}\right)$. Therefore the seasonal characteristics can be removed by dividing $H_{B}{ }^{\prime}(t)$ and $H_{C}{ }^{\prime}(t)$ by $H_{A}\left(t_{i}\right)$.

$$
H_{B}\left(t_{i}\right)=H_{B}{ }^{\prime}\left(t_{i}\right) / H_{A}\left(t_{i}\right) \quad H_{C}\left(t_{i}\right)=H_{C}{ }^{\prime}\left(t_{i}\right) / H_{A}\left(t_{i}\right) \quad(i=1, \cdots, 4380)
$$

Figures 7(a) and 7(b) show $H_{B}\left(t_{i}\right)$ and $H_{C}\left(t_{i}\right)$, respectively. Corresponding $H_{B}{ }^{\prime}\left(t_{i}\right)$ and $H_{C}{ }^{\prime}\left(t_{i}\right)$ are shown in Figs. 5(c) and 5(d). Seasonal characteristics of Figs. 5(c) and 5(d) are not seen in the figures. Since the spectrum width of $H_{B}\left(t_{i}\right)$ and $H_{C}\left(t_{i}\right)$ are very narrow and their monthly standard deviations are almost constant, it can be assumed that these wave forms are stationary. 


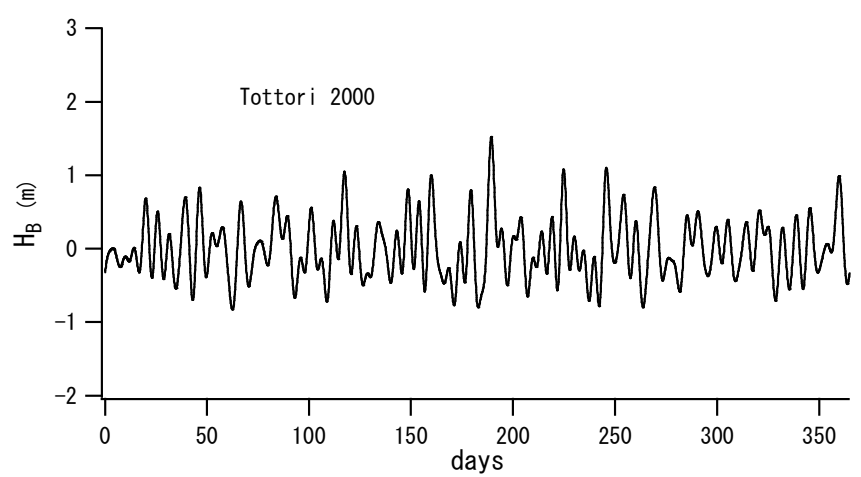

(a) $H_{B}\left(t_{i}\right)$

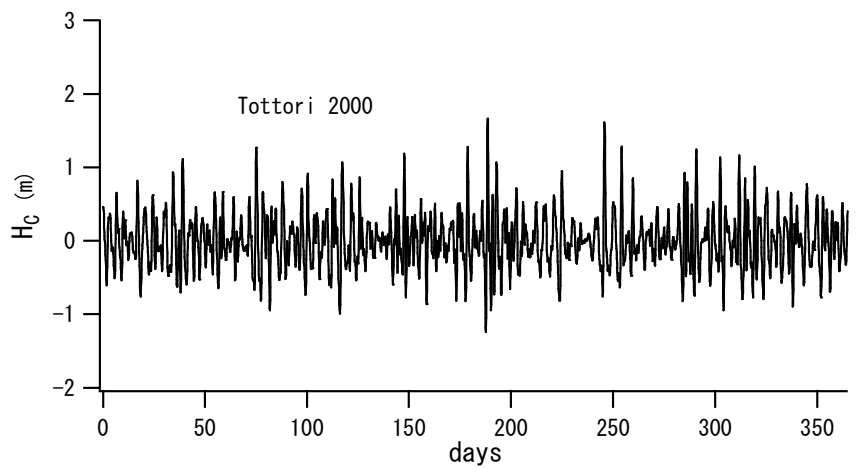

(b) $H_{C}\left(t_{i}\right)$

Figure 7. Seasonal characteristics are removed from data in Figs. 5(c) and 5(d) using eq.(4) (Tottori, 2000).

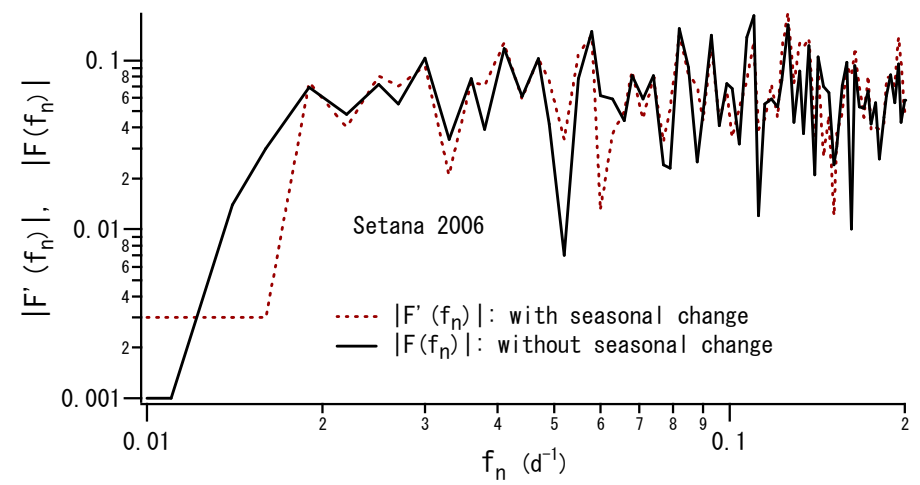

(a) Comparison of the spectrum of $H_{B}{ }^{\prime}\left(t_{i}\right)$ and $H_{B}\left(t_{i}\right)$

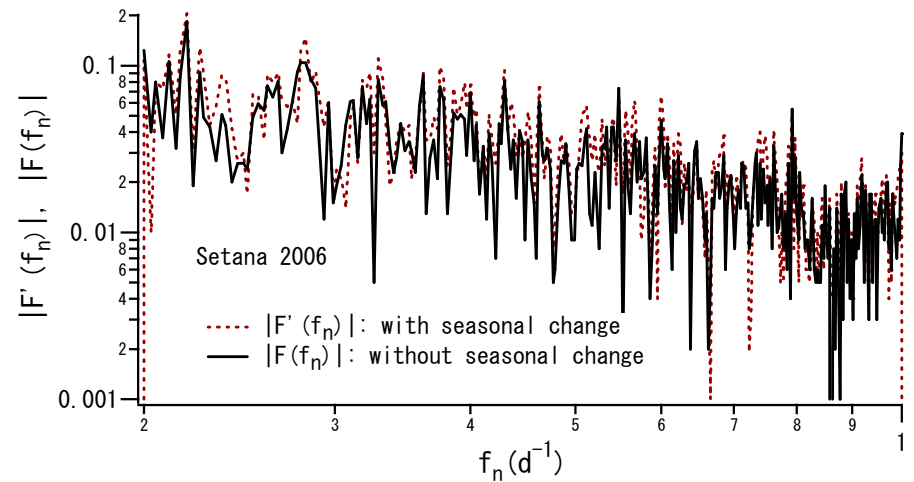

(b) Comparison of the spectrum of $H_{C}{ }^{\prime}\left(t_{i}\right)$ and $H_{C}\left(t_{i}\right)$

Figure 8. Comparison of the spectrum with and without seasonal characteristics (Setana,2006). 


$$
\left.\begin{array}{ll}
F\left(f_{n}\right)=\sum_{i=1}^{4380} H_{\mathrm{B}}\left(t_{i}\right) \exp \left(-j 2 \pi f_{n} t_{i}\right), & (n=3, \cdots, 73) \\
F\left(f_{n}\right)=\sum_{i=1}^{4380} H_{\mathrm{C}}\left(t_{i}\right) \exp \left(-j 2 \pi f_{n} t_{i}\right), \quad(n=74, \cdots, 731)
\end{array}\right\}
$$

Figures 8(a) and 8(b) show comparisons between the spectra for (a) $H_{B}{ }^{\prime}\left(t_{t}\right)$ and $H_{B}\left(t_{i}\right)$ and (b) $H_{C}{ }^{\prime}\left(t_{t}\right)$ and $H_{C}\left(t_{i}\right)$ (Setana, 2006). There are no significant changes in the spectra before and after the removal of the seasonal characteristics.

\section{Phase of $F\left(f_{n}\right)$}

From eq.(5), phase spectrum of $F\left(f_{n}\right)$ is given as

$$
\varepsilon_{n}=\tan ^{-1}\left\{-\frac{\operatorname{Im}\left(F\left(f_{n}\right)\right)}{\operatorname{Re}\left(F\left(f_{n}\right)\right)}\right\} \quad(n=3,4, \cdots, 731)
$$

in which $\operatorname{Re}(\quad)$ and $\operatorname{Im}(\quad)$ mean the real and imaginary parts, respectively. Figures 9 (a) and 9(b) show frequency distributions $F R\left(\varepsilon_{n}\right)$ of $\varepsilon_{n}$ every year for (a) $H_{B}\left(t_{i}\right)$ (Hamada) and (b) $H_{C}\left(t_{i}\right)$ (Wajima). The distributions are almost uniforms.

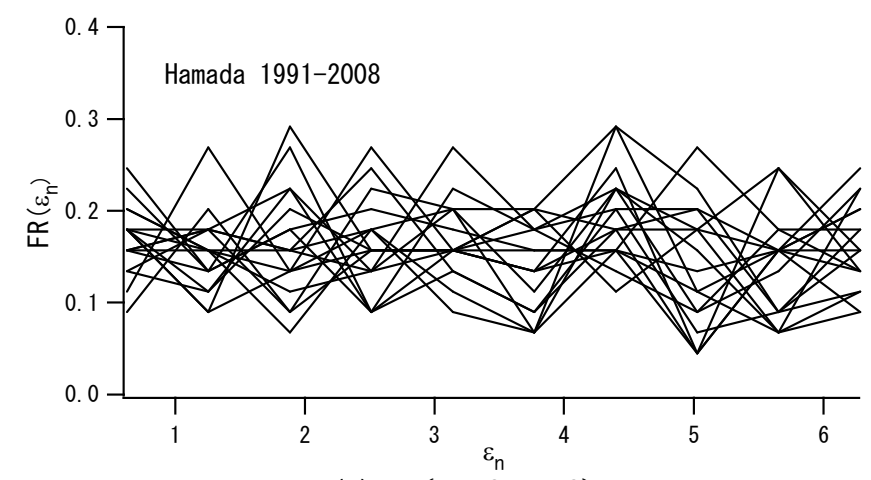

(a) $\varepsilon_{n}(n=3, \cdots, 73)$

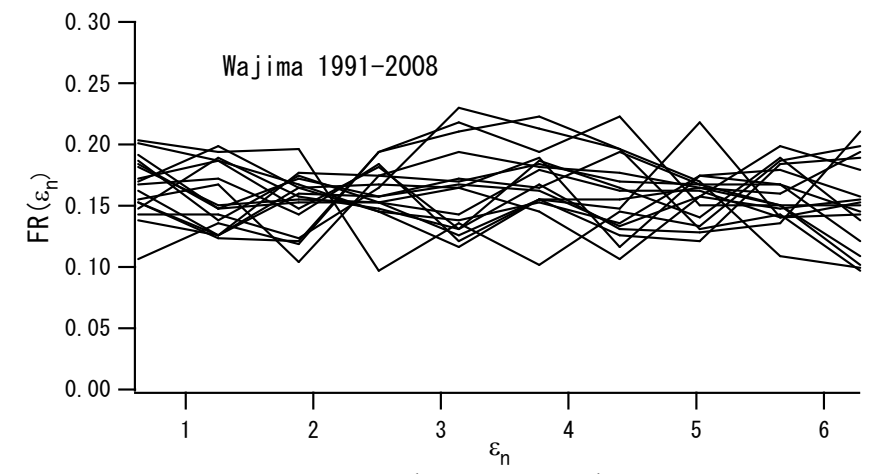

(b) $\varepsilon_{n}(n=74, \cdots, 731)$

Figure 9. Frequency distributions of the phase of (a) $H_{B}$ (Hamada) and (b) $H_{C}$ (Wajima)

\section{MODELING OF $H_{1 / 3}(t)$}

Equation (2) is rewritten as,

$$
H_{1 / 3}\left(t_{i}\right)=H_{A}\left(t_{i}\right)\left\{1+H_{B}\left(t_{i}\right)+H_{C}\left(t_{i}\right)\right\} \quad(i=1, \cdots, 4380)
$$

Spectrum of $H_{B}\left(t_{i}\right)$ and $H_{C}\left(t_{i}\right)$ are approximated simply as (Fig.4),

$$
\left.\begin{array}{l}
\left|F\left(f_{n}\right)\right|_{B}=\alpha_{1} \\
\left|F\left(f_{n}\right)\right|_{C}=\alpha_{2} f^{-1}
\end{array}\right\}
$$

in which $\left|F\left(f_{n}\right)\right|_{B}$ and $\left|F\left(f_{n}\right)\right|_{C}$ are the absolute values of the model spectrum in the regions $\mathrm{A}$ and $\mathrm{B}$ respectively, $\alpha_{1}$ and $\alpha_{2}$ are constants determined by the least square principle. 


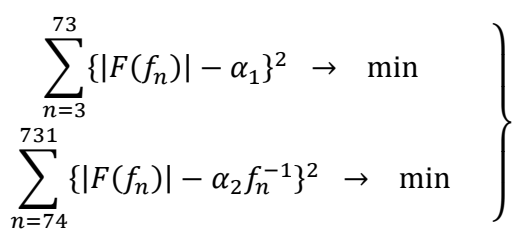

Calculated $\alpha_{1}$ and $\alpha_{2}$ show almost constant value with small fluctuations. Figure 10 shows an example of the values (Akita, 1991 - 2008).

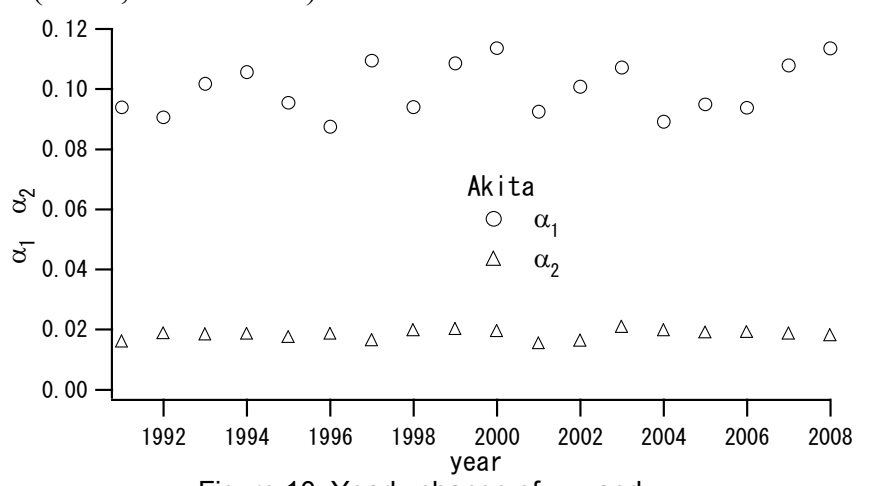

Figure 10. Yearly change of $\alpha_{1}$ and $\alpha_{2}$

Normal distributions for the fluctuation of $\alpha_{1}$ and $\alpha_{2}$ are assumed. Their means and standard deviations $\bar{\alpha}_{1}, \bar{\alpha}_{2}$ and $\alpha_{\sigma 1}, \alpha_{\sigma 2}$ are calculated from the observed data.

SIMULATION OF $H_{1 / 3}(t)$

From eq.(7), $H_{1 / 3}(t)$ is approximated as

$$
\begin{gathered}
H_{1 / 3}\left(t_{i}\right)=H_{A}\left(t_{i}\right)\left\{1+\sum_{n 1=3}^{73}\left(\bar{\alpha}_{1}+\alpha_{\sigma 1} R_{n 1}\right) \cos \left(2 \pi f_{n 1} t_{i}+\varepsilon_{n 1}\right)\right. \\
\left.+\sum_{n 2=74}^{731}\left(\bar{\alpha}_{2}+\alpha_{\sigma 2} R_{n 2}\right) f_{n 2}^{-1} \cos \left(2 \pi f_{n 2} t_{i}+\varepsilon_{n 2}\right)\right\} \\
t_{i}=i d t \quad(i=0,1, \cdots) \\
\varepsilon_{n 1}=2 \pi R_{U n 1}, \quad \varepsilon_{n 2}=2 \pi R_{U n 2}
\end{gathered}
$$

where $R_{n 1}$ and $R_{n 2}$ are independent normal random numbers with 0 mean and 1.0 standard deviation, $R_{U n 1}$ and $R_{U n 2}$ are also independent uniform random number $(0 \sim 1)$. If $d t<d / 4$, any value can be used for $d t$ in eq.(10). However, it is preferable to use the same value as the observed data interval. $H_{A}(t)$ is approximated as

$$
\begin{gathered}
H_{A}\left(t_{i}\right) \approx \bar{H}_{A}\left(t_{i}\right)+H_{\sigma}\left(t_{i}\right) R_{n 3} \\
\bar{H}_{A}\left(t_{i}\right)=\frac{1}{2} \bar{a}_{0}+\sum_{n=1}^{2}\left\{\bar{a}_{\mathrm{n}} \sin \left(2 \pi f_{n} t_{i}\right)+\bar{b}_{n} \cos \left(2 \pi f_{n} t_{i}\right)\right\} \\
H_{\sigma}\left(t_{i}\right)=\left\{\frac{1}{18} \sum_{m=1991}^{2008}\left[H_{A m}\left(t_{i}\right)-\bar{H}_{A}\left(t_{i}\right)\right]^{2}\right\}^{1 / 2} \quad(i=1,2, \cdots, 4380)
\end{gathered}
$$

in which $\bar{a}_{n}=\operatorname{Re}\left\{\overline{F^{\prime}}\left(f_{n}\right)\right\}, \bar{b}_{n}=\operatorname{Im}\left\{\overline{F^{\prime}}\left(f_{n}\right)\right\},(n=0,1,2)$ and $\overline{F^{\prime}}\left(f_{n}\right)$ is an average of 18 years $F^{\prime}\left(f_{n}\right)$ \{eq. (1)\}. $\bar{H}_{A}\left(t_{i}\right)$ is an average of 18 years $H_{A}\left(t_{i}\right) . H_{A m}\left(t_{i}\right)$ is the $m$-th year (1991 2008) value of $H_{A}\left(t_{i}\right)$. $H_{\sigma}\left(t_{i}\right)$ is a standard deviation of 18 years $H_{A m}\left(t_{i}\right) . R_{n 3}$ is a normal random number with 0 mean and 1.0 standard deviation. One year uses the value of same $R_{n 3}$.

If the observation years are not sufficiently long, following definition for $H_{A}\left(t_{i}\right)$ can be used instead of eq.(12a).

$$
H_{A}\left(t_{i}\right) \approx \bar{H}_{A}\left(t_{i}\right)+\bar{H}_{\sigma} R_{n 3}
$$

in which $\bar{H}_{\sigma}$ is an average of $H_{\sigma}\left(t_{i}\right),(\mathrm{i}=1, \cdots, 3840)$. One year uses also the value of same $R_{n 3}$. Since $H_{\sigma}\left(t_{i}\right)$ itself and its fluctuation are small, there are no big differences between eqs.(12a) and (12b).

Constants for the simulation at each observatory are listed in the Table 2. 


\begin{tabular}{|c|c|c|c|c|c|c|c|}
\hline \multicolumn{7}{|c|}{ Table 2 Constants for the simulation } \\
\hline & Rumoi & Setana & Akita & Niigata & Wajima & Tottori & Hamada \\
\hline $\bar{a}_{0}$ & 1.119 & 1.188 & 1.088 & 1.000 & 1.197 & 1.093 & 1.119 \\
\hline $\bar{a}_{1}$ & 0.777 & 0.805 & 0.680 & 0.726 & 0.777 & 0.650 & 0.597 \\
\hline $\bar{b}_{1}$ & 0.093 & 0.088 & 0.144 & 0.106 & 0.093 & 0.062 & 0.081 \\
\hline $\bar{a}_{2}$ & 0.150 & 0.057 & 0.120 & 0.142 & 0.150 & 0.101 & 0.091 \\
\hline $\bar{b}_{2}$ & 0.067 & -0.022 & 0.020 & 0.077 & 0.067 & 0.078 & 0.083 \\
\hline $\bar{H}_{\sigma}$ & 0.107 & 0.120 & 0.138 & 0.108 & 0.129 & 0.111 & 0.123 \\
\hline $\bar{\alpha}_{1}$ & 0.0818 & 0.0817 & 0.1000 & 0.0824 & 0.0741 & 0.0777 & 0.0778 \\
\hline$\alpha_{\sigma 1}$ & 0.00718 & 0.00594 & 0.00860 & 0.00634 & 0.00462 & 0.00557 & 0.00722 \\
\hline $\bar{\alpha}_{2}$ & 0.0155 & 0.0150 & 0.0184 & 0.0157 & 0.0130 & 0.0134 & 0.0137 \\
\hline$\alpha_{\sigma 2}$ & 0.00093 & 0.00085 & 0.00150 & 0.00107 & 0.00101 & 0.00105 & 0.00128 \\
\hline
\end{tabular}

Uinit: $m / d: \overline{\alpha_{2}}, \alpha_{\sigma 2}, m$ : otherwise.

\section{CORRECTION AND RESULTS}

Figures 11(a) and 11(b) show observed and simulated one year $H_{1 / 3}(t)$ (Hamada).

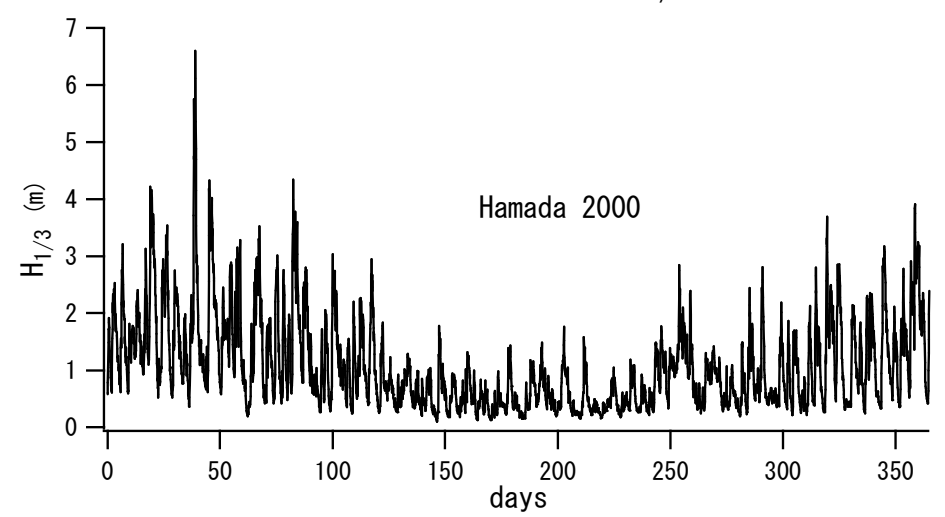

(a) $H_{1 / 3}(t)$ (observed)

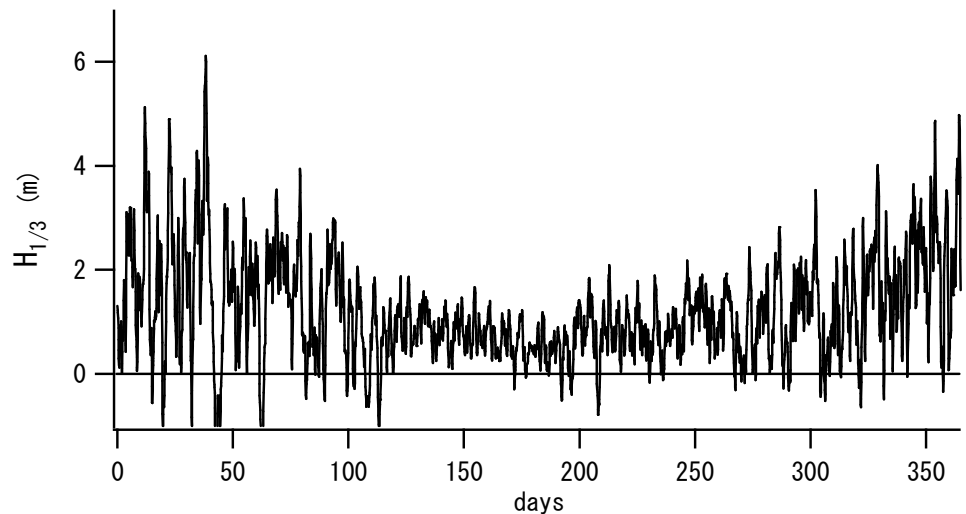

(b) $H_{1 / 3}(t)$ (simulated)

Figure 11. Observed (Hamada, 2000) and simulated one year $H_{1 / 3}(t)$ (Hamada)

\section{Correction}

Simulated $H_{1 / 3}(t)$ in Fig.11(b) shows a similar seasonal characteristic to Fig.11(a). However some data show negative value. Figure 12 shows frequency distributions of the observed $\left\{P_{o b s}\left(H_{1 / 3}\right)\right.$; solid line, Wajima $1991-2008\}$ and simulated $\left\{P_{\text {sim }}\left(H_{1 / 3}\right)\right.$; dotted line Wajima ; 10000 years simulation $\} H_{1 / 3}(t)$. 


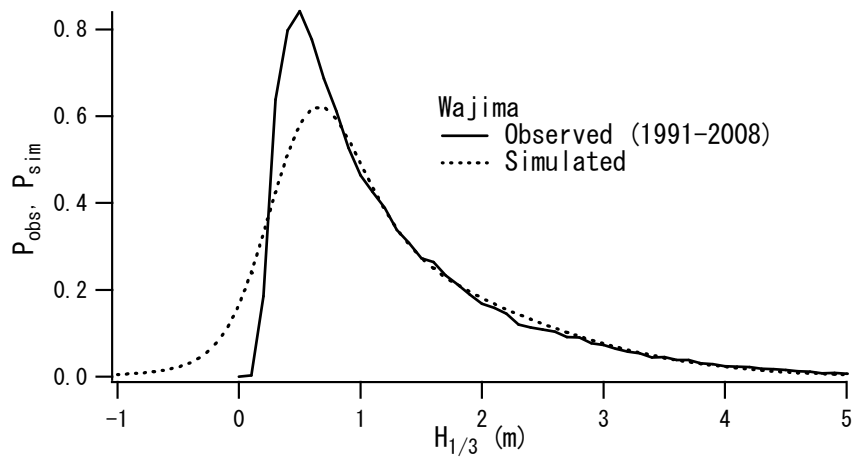

Figure 12. Frequency distributions of observed (solid line) and simulated (dotted line) $H_{1 / 3}(t)$

There is a difference between $P_{o b s}\left(H_{1 / 3}\right)$ and $P_{\text {sim }}\left(H_{1 / 3}\right)$ in the area of $H_{1 / 3}(t)<1.0 \mathrm{~m}$. About $2 \%$ in all the simulated values are negative. However $P_{\text {obs }}\left(H_{1 / 3}\right)$ and $P_{\text {sim }}\left(H_{1 / 3}\right)$ show good agreement in the area of $H_{1 / 3}(t)>1.0 \mathrm{~m}$. In this study, data are corrected applying frequency distribution conversion method. The conversion is made using the cumulative distributions which are calculated as,

$$
\left.\begin{array}{c}
F_{o b s}\left(H_{1 / 3}\right)=\sum_{H=0}^{H_{1 / 3}} P_{o b s}(H) d H \\
F_{\text {sim }}\left(H_{1 / 3}\right)=\sum_{H=-\infty}^{H_{1 / 3}} P_{\text {sim }}(H) d H
\end{array}\right\}
$$

in which $F_{o b s}$ and $F_{\text {sim }}$ are the cumulative distributions of $P_{o b s}$ and $P_{s i m}$ respectively. Data are converted using the following relation.

$$
F_{\text {sim }}\left\{\left(H_{1 / 3}\right)_{\text {in }}\right\}=F^{*}\left\{\left(H_{1 / 3}\right)_{\text {out }}\right\}
$$

in which $F^{*}$ is a target cumulative distribution to converted the data from the simulated data. For the target distribution, $F^{*}$ must be $0\left(H_{1 / 3} \leq 0\right)$ and very close to $F_{o b s}\left(H_{1 / 3}>0\right)$. However if the observation period is not sufficiently long, uneven properties appear on the $F_{o b s}$. In that case, modified cumulative distribution of $F_{\text {sim }}$ can be used. Figure 13 shows a modification of the frequency distribution. Dotted line shows $P_{\text {obs }}-P_{\text {sim }}$. Solid line shows the function $E_{\text {mod }}$ to modify $P_{\text {sim }} . E_{\text {mod }}$ is given as

$$
E_{\text {mod }}\left(H_{1 / 3}\right)=\left\{\begin{array}{lc}
-P_{\text {sim }}\left(H_{1 / 3}\right) & \text { A: } H_{1 / 3} \leq I_{1} \\
\left\{2 \frac{H_{1 / 3}-I_{1}}{I_{2}-I_{1}}-1\right\} P_{\text {sim }}\left(I_{1}\right) & I_{1} \leq H_{1 / 3} \leq I_{2} \\
P_{\text {sim }}\left(I_{2}+I_{1}-H_{1 / 3}\right) & \text { B }: H_{1 / 3} \geq I_{2}
\end{array}\right.
$$

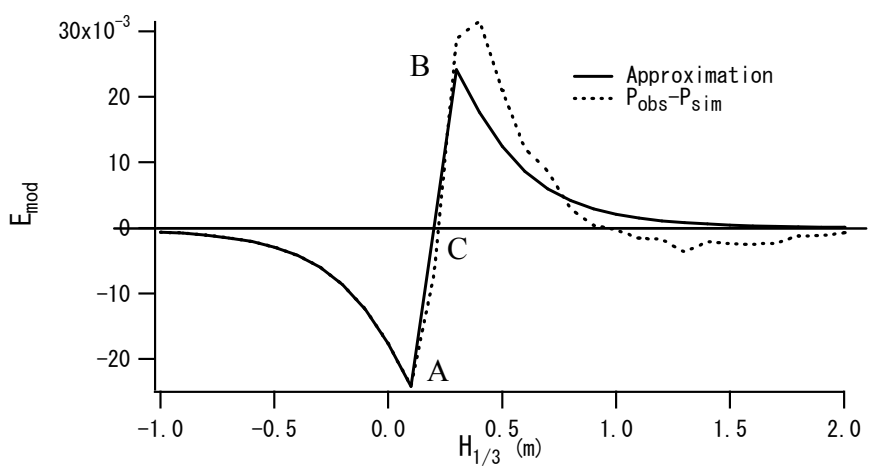

Figure 13. Modification of the frequency distribution

$E_{\text {mod }}$ is a straight line between the points A and B (Fig.13). $E_{\text {mod }}$ is point symmetric for C: $\left(I_{2}-I_{1}\right) / 2,0$. $I_{1}$ and $I_{2}$ are determined so that difference between $P_{o b s}-P_{\text {sim }}$ and $E_{\text {mod }}$ becomes minimum $\left(H_{1 / 3} \geq I_{1}\right)$. In Fig. $13, I_{1}=0.1 \mathrm{~m}$ and $I_{2}=0.3 \mathrm{~m}$. Modified frequency distribution $P_{\text {sim }}^{*}$ is given by

$$
P_{\text {sim }}^{*}\left(H_{1 / 3}\right)=P_{\text {sim }}\left(H_{1 / 3}\right)+E_{\text {mod }}\left(H_{1 / 3}\right)
$$

Substituting $P_{\text {sim }}^{*}$ in eq.(15), its cumulative distribution $F_{\text {sim }}^{*}$ is calculated. 


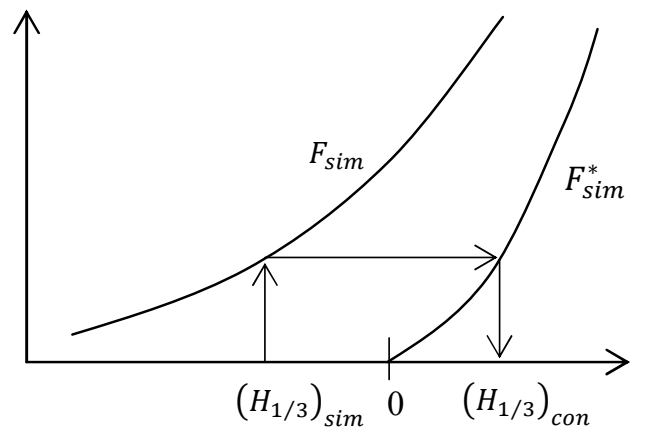

Figure 14. Conversion of the data.

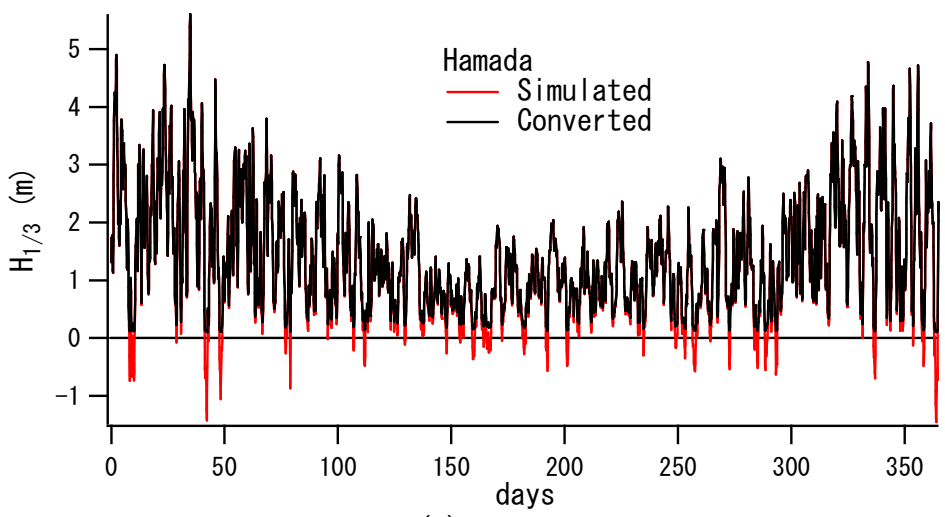

(a) one year

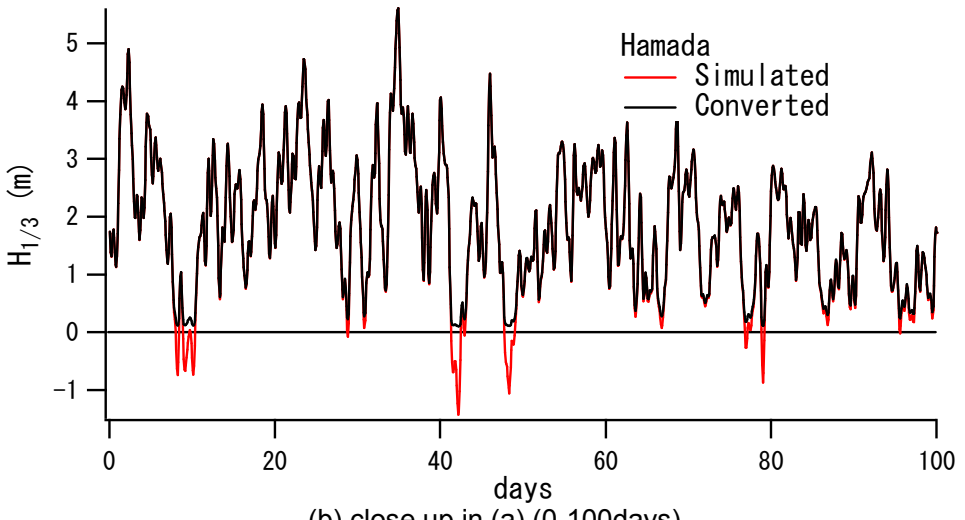

(b) close up in (a) (0-100days)

Figure 15. Comparison between simulated data (red line) and converted data (black line) of (a) one year, (b) 0 to 100 days (close up in the Fig.15(a))

Figure 14 shows a pattern diagram of the conversion. $\left(H_{1 / 3}\right)_{\text {sim }}$ and $\left(H_{1 / 3}\right)_{c o n}$ in the figure are the simulated (eq.10, Fig.11(b)) and the converted data respectively. Figure 15(a) shows the comparison between simulated (red line) and converted (black line) $H_{1 / 3}$. Figure $15(\mathrm{~b})$ is a close up in Fig.15(a) (1 100days). Data is properly converted. No substantial change takes place except for $H_{1 / 3}<0.5 \mathrm{~m}$.

\section{Results}

The calculations are executed in the following procedures.

1. Simulation of $\mathrm{H}_{1 / 3}$ (eq.10).

2. Calculation of a frequency and cumulative distributions of simulated $H_{1 / 3}\left(P_{\text {sim }}, F_{\text {sim }}\right)($ eq.15).

3. Modification of $P_{\text {sim }}\left(P_{\text {sim }}^{*}:\right.$ eqs.17 and 18).

4. Calculation of $F_{\text {sim }}^{*}$ (eq.15).

5. Data conversion (eq.16, Fig.14) using $F_{\text {sim }}$ and $F_{\text {sim }}^{*}$ or $F_{\text {obs }}$.

6. Calculation of a frequency distribution of wave climate $P_{w c l}$ and its cumulative distribution $F_{w c l}$ (eq.15), where $P_{w c l}$ is a frequency distribution of $\left(H_{1 / 3}\right)_{c o n}$ (Fig.14). Calculated $P_{w c l}$ and $F_{w c l}$ are distributions for $H_{1 / 3}$ every $d t$ hour.

If $F_{o b s}$ is used, the procedure 3 and 4 are not necessary. 
Figure 16 shows frequency distributions of the converted $\left(H_{1 / 3}\right)_{\text {con }}$ (solid black line), observed $H_{1 / 3}$ (red line) and the modified frequency distribution $P_{\text {sim }}^{*}$ (dotted line). Distribution of the converted $H_{1 / 3}$ agrees well with the modified (target) distribution.

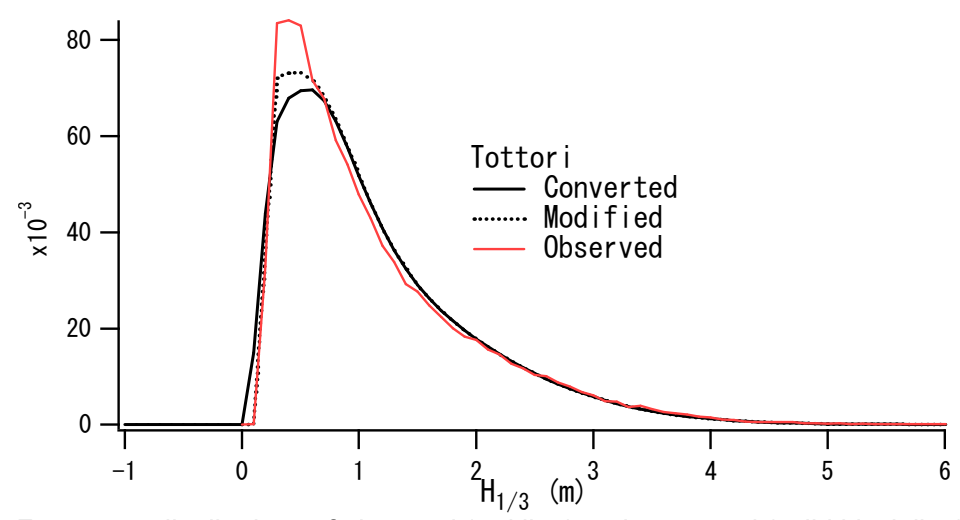

Figure 16. Frequency distributions of observed (red line) and converted (solid black line) wave heights and $P_{\text {sim }}^{*}$ (dotted line) used for the conversion. $F_{\text {sim }}^{*}$ is used for the conversion.

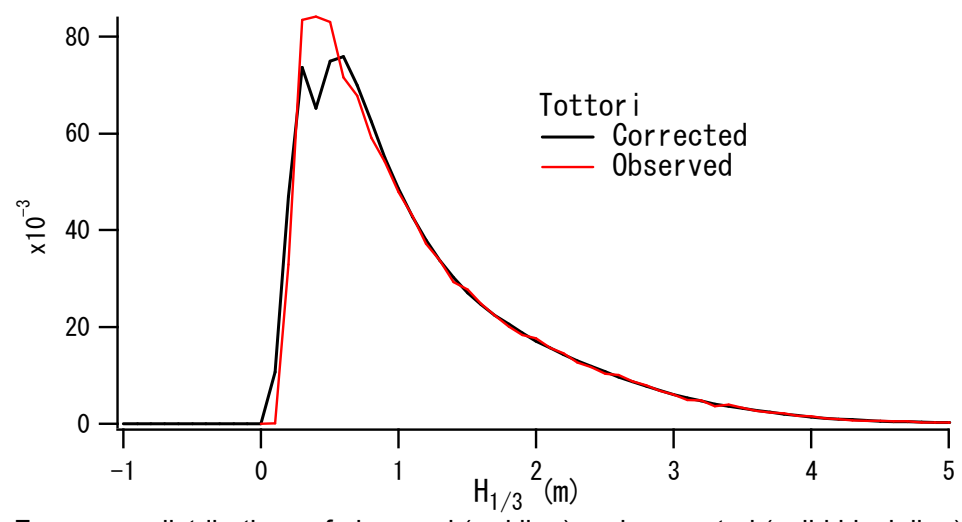

Figure 17. Frequency distributions of observed (red line) and converted (solid black line) wave heights.

$F_{o b s}$ is use for the conversion.

Figure 17 shows a frequency distribution of the observed (red line) and converted (solid black line) $H_{1 / 3} . F_{\text {obs }}$ was used for the conversion. Good agreements between observed and converted distributions are obtained in the Figs. 16 and 17.

\section{APPLICATIONS}

First of all, frequency distributions of the necessary properties are calculated from the sufficient number of simulated and converted data.

Probability that $H_{1 / 3}$ exceeds a certain threshold value $H_{*}$ is given by,

$$
F_{\text {ttla }}\left(H_{*}\right)=\sum_{H_{1 / 3}>H_{*}}^{\infty} P_{w c l}\left(H_{1 / 3}\right) d H_{1 / 3}
$$

in which $P_{w c l}$ is the frequency distribution of $\left(H_{1 / 3}\right)_{c o n}$ (Fig.14). When information at the limited period of a year (Apr. Aug., for example) is necessary, $P_{w c l}$ in the limited period is used. The wave height at the concerned period is chosen from one year $H_{1 / 3}$. Other calculations follow the procedure from 2 to 6 .

Total hour $T_{\text {expa }}$ for $H_{1 / 3}$ to exceed a threshold value $H_{*}$ in a limited period $T_{P}$ (days) is calculated as $T_{\text {expa }}=F_{\text {ttla }}\left(H_{*}\right) \times\left(24 \times T_{P}\right)$ (hours $\left./ T_{P}\right)$. On the contrary, the frequency that $H_{1 / 3}$ falls below $H_{*}$ in the period $T_{P}$ is given by,

$$
F_{t t l b}\left(H_{*}\right)=1-F_{t t l a}\left(H_{*}\right)
$$

Total hour $T_{\text {expb }}$ is also given by $T_{\text {expb }}=F_{t t l b}\left(H_{*}\right) \times\left(24 \times T_{P}\right)$.

Figure 18 shows $T_{\text {expa }}$ for (a) $H_{*}=1.0 \mathrm{~m}$ (Akita) and (b) $H_{*}=1.5 \mathrm{~m}$ (Tottori). If $T_{P}$ is a period for a maintenance work, $T_{\text {expa }}$ is a total hours in which the work is difficult. Three periods $T_{P}=60,90$ and 120 days are used, for examples. Starting day is changed from the $60^{\text {th }}$ to $220^{\text {th }}$ days of a year. To make these figures, 10000 years simulation for $H_{1 / 3}$ (every 2 hours) were conducted. 


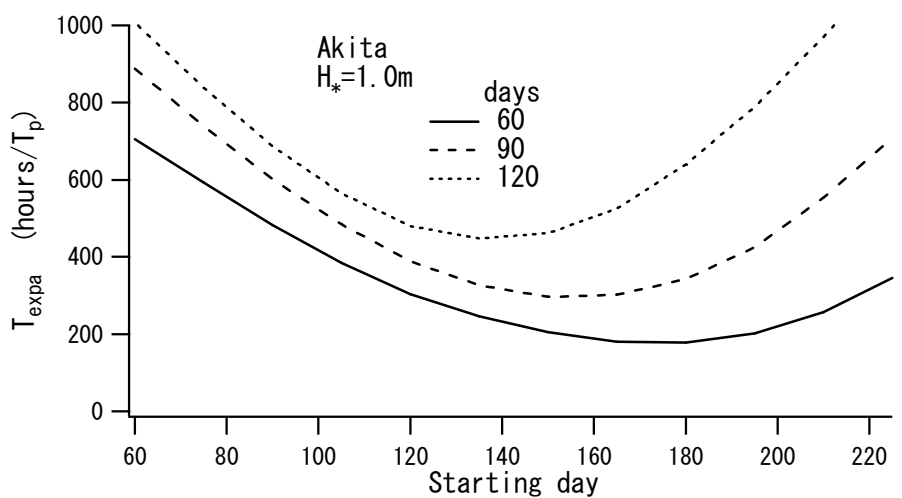

(a) Akita

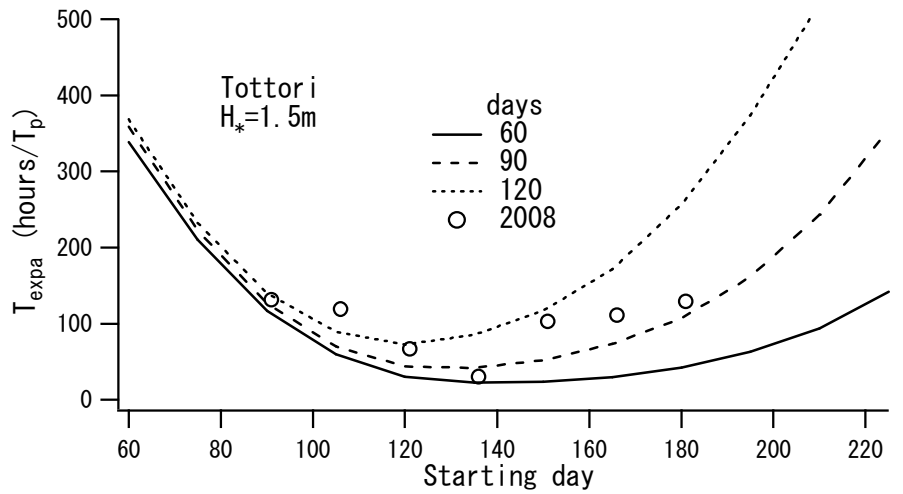

(b) Tottori

Figure 18. Expected total hours for $H_{1 / 3}$ to exceed $H_{*}$ (a) (Akita, $H_{*}=1.0 \mathrm{~m}$ ), (b) (Tottori, $H_{*}=1.5 \mathrm{~m}$ )

in 60 days (solid line), 90 days (broken line) and 120 days (dotted line) period.

Circles in the figure (b) are calculated from the observed $H_{1 / 3}$ in 2008 (90 day period).

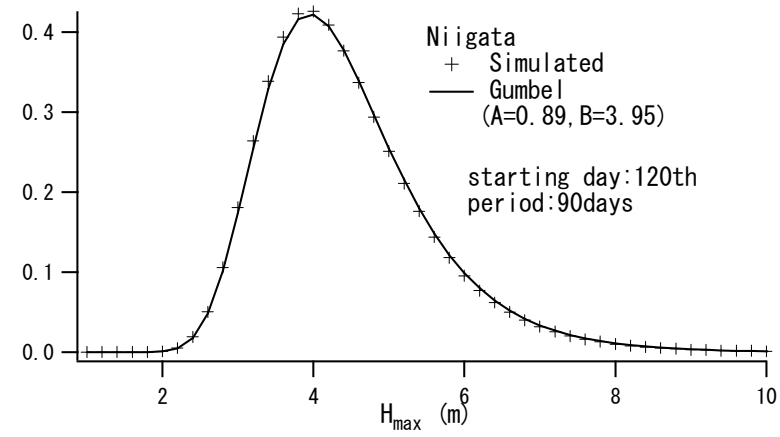

(a) Niigata

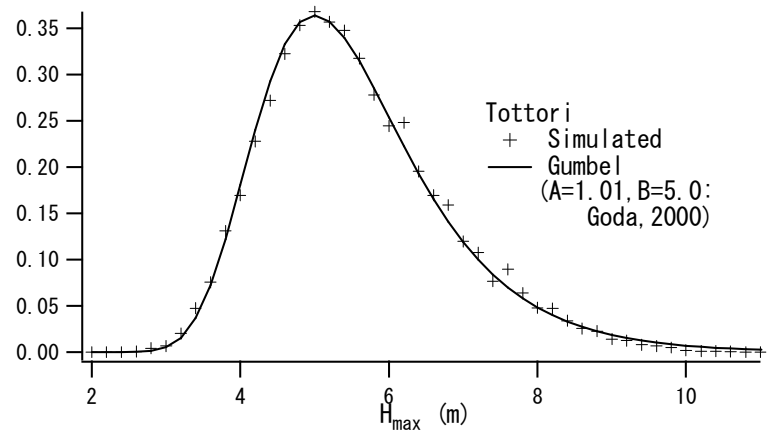

(b) Tottori

Figure 19. Frequency distribution of the maximum $H_{1 / 3}$ in (a) 90 days from the $120^{\text {th }}$ day of a year and (b) one year (Niigat). 


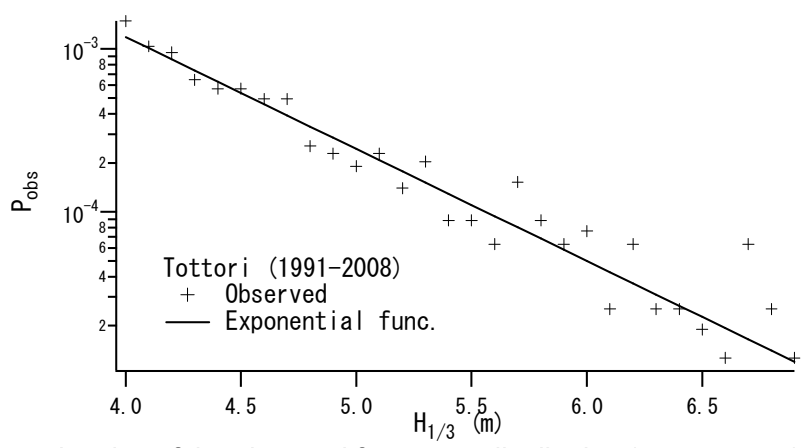

Figure 20. Partial approximation of the observed frequency distribution $\left(H_{1 / 3} \geq 4.0 \mathrm{~m}\right)$ by exponential function.

In Akita (Fig.18(a), $\left.H_{*}=1.0 \mathrm{~m}\right)$, the best starting days are around $130^{\text {th }}$ day $\left(T_{P}=120\right.$ days $), 160^{\text {th }}$ day $\left(T_{P}=90\right.$ days) and $180^{\text {th }}$ day ( $T_{P}=60$ days) of the year respectively. In Tottori (Fig.18(b), $H_{*}=1.5 \mathrm{~m}$ ), the best starting day is almost the same $\left(130^{\text {th }}\right.$ day) regardless of $T_{P}$. If the maintenance work is planned to finish during a small $H_{*}$ period, starting day must be decided very carefully. The maximum $H_{1 / 3}$ during the period can be calculated also from the simulated data. This information may be necessary to prepare protections of the maintenance site from high waves. Figure 19(a) shows an example of a frequency distribution of the maximum $H_{1 / 3}$ in $T_{P}=90$ days. Stating day is $120^{\text {th }}$ day (Niigata). Gumbel distribution (solid line) is shown for the comparison. The data distribution is corresponding to the Gumbel distribution very well.

Frequency distribution of the annual maximum $H_{1 / 3}\left(T_{P}=365\right.$ days $)$ can be calculated also from the same simulated data. Figure 19(b) shows a frequency distribution of an annual maximum significant wave height $H_{\max }$ (Tottori). Simulated data distribution $P_{\text {sim }}^{*}$ was used in the conversion. When $P_{\text {obs }}$ is used, ruggedness appears on the distribution. This may due to the insufficient number of observed data. Even when the simulated data is used from 10000 years simulation, for example, the ruggedness appears in a large wave height region. Since $P_{o b s}$ and $P_{\text {sim }}$ agree well with exponential functions in a large $H_{1 / 3}$ region, it is preferable to approximate them using exponential functions in the region. Figure 20 shows an example of the approximation.

\section{Return period and design wave height}

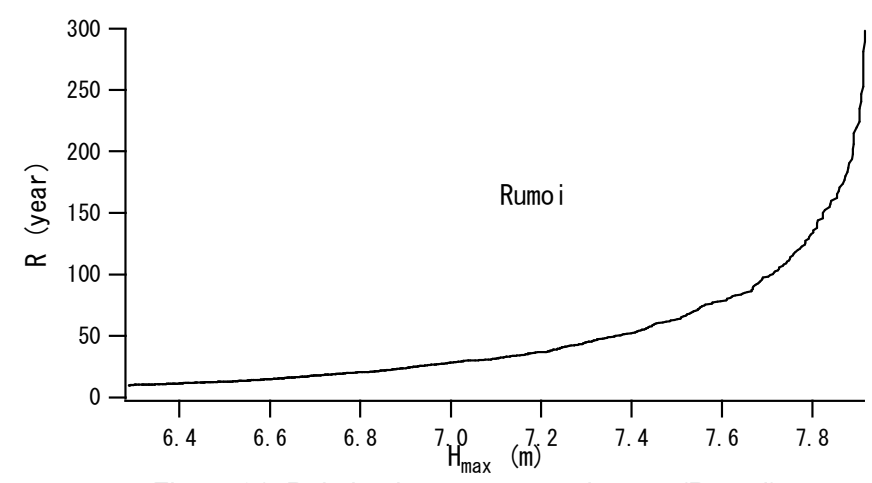

Figure 21. Relation between $R$ and $H_{\max }$ (Rumoi)

Return period $R$ of $H_{\max }$ has been used for design of coastal structures. $H_{\max }$ is given by (Goda, 2000),

$$
R=\frac{1}{1-F\left(H_{\max }\right)}
$$

in which $F\left(H_{\max }\right)$ is the cumulative distribution of $H_{\max }$. Cumulative distribution of the simulated $H_{\max }$ is used for $F\left(H_{\max }\right)$ in this study. Figure 21 shows an example of the relation between $R$ and $H_{\max }$ (Rumoi).

When $H_{\max }$ is determined giving the return period $R$, the probability that bigger waves than $H_{\max }$ arrive in $R$ years is about 0.63 . $H_{\max }$ for $R=50$ (years) is $7.4 m$ in this case (Fig.21). Total hours $T_{t l}$ that $H_{1 / 3}$ exceeds $7.4 m$ in 50 years is given as,

$$
T_{t l}=24 \times 365 \times 50 \times \sum_{H_{1 / 3}=7.4 m}^{\infty} P_{w c l}\left(H_{1 / 3}\right)=25.2 \text { (hours/50years) }
$$

in which $P_{w c l}\left(H_{1 / 3}\right)$ is the frequency distribution of the simulated one year $H_{1 / 3}$.

The frequency distribution of the waves which exceeds the design wave height can be also calculated using the present method. 


\section{CONCLUDING REMARKS}

The present study deals with a statistics of wave climate especially significant wave height $H_{1 / 3}$. NOWPHAS data from 7 observatories along the Sea of Japan coast is investigated. The present study did not follow the same procedure that early researches adopted. Instead of studying the time series of $H_{1 / 3}$ directly in a time domain, its statistical characteristic in frequency domain is studied and clarified that Fourier spectrum has an inherent characteristic to the monsoon region. The spectrum can be divided into three frequency regions; (A) $f<$ $0.006 d^{-1}$, (B) $0.006 d^{-1}<f<0.2 d^{-1}$ and (C) $0.2 d^{-1}<f<2 d^{-1}$ where $d^{-1}=1$ /day. In the region (A), the lowest three frequency components are involved. These components give a seasonal monsoon characteristic. The spectra in the (B) and (C) regions have very simple structures. An easy modeling was proposed in this study. Monte-Carlo simulations were conducted using the model. Methods to derive frequency distributions of wave height for arbitrary specified period including one year are explained. All statistical properties can be derived from the numerically simulated data. No formulation for the frequency distribution of wave properties is necessary. Statistical characteristics of wave climate may show us new possible applications not only for the lifecycle management of structures.

More detailed examination concerning the assumptions in eqs.(8) and (10) is preferable to make clear the statistical reliability of the results. Investigation on the validity of the spectrum modeling is another problem. Since wave height is not the property which changes around a certain mean value, but changes always from 0 only into a positive side. This difference may cause some error margins to the values in the region (C).

Comparisons with existing researches such as extreme wave statistics are also important.

\section{ACKNOWLEDGMENTS}

NOWPHAS (Nationwide Ocean Wave information network for Port and HArbourS) data is used in this study. The authors express their thanks to the Port and Airport Research Institute which organizes the data acquisition network syste.

\section{REFERENCES}

Goda, Y. 2000. Random seas and design of maritime structures. World Scientific, Advanced Series on Ocean Engineering-Vol. 15, 443p.

Hirose, S., and T. Takahashi . 1982. Appearance characteristics of observed coastal waves. Lecture Collection of the Port and Harbour Research Institute. 